04.1;05.1

\title{
Влияние наносекундного искрового разряда на косое соударение стального шара с металлической плитой
}

\author{
() А.Е. Дубинов ${ }^{1,2}$, Дж.Н. Исхакова ${ }^{2}$, В.А. Любимцева ${ }^{1}$ \\ ${ }^{1}$ Российский федеральный ядерный центр - Всероссийский научно-исследовательский институт экспериментальной \\ физики, Саров, Нижегородская обл., Россия \\ ${ }^{2}$ Саровский физико-технический институт — филиал Научно-исследовательского ядерного университета „МИФИ“, \\ Саров, Нижегородская обл., Россия \\ E-mail: dubinov-ae@yandex.ru
}

Поступило в Редакцию 8 декабря 2021 г.

В окончательной редакции 2 января 2022 г.

Принято к публикации 10 января 2022 r.

\begin{abstract}
Экспериментально изучено влияние наносекундного искрового разряда на косое соударение стального шара с плоской чугунной плитой. Найдено, что угол отражения шара при столкновении с разрядом становится меньше угла подлета, в то время как при обычном соударении без разряда, наоборот, угол отражения больше угла подлета.
\end{abstract}

Ключевые слова: соударение твердых тел, искровой разряд, углы падения и отражения.

DOI: 10.21883/PJTF.2022.06.52209.19102

Соударение тела с тяжелой преградой представляет собой фундаментальное явление, которое изучалось исследователями с древних времен. Основополагающее исследование упругих соударений шаров с преградой применительно к бильярдной игре было выполнено Кориолисом в начале XIX века [1].

Давно было известно, что в идеальном случае при абсолютно упругом соударении кинетическая энергия сохраняется, а при косом соударении, кроме того, угол подлета $\theta_{i}$ равен углу отражения $\theta_{r}$. В общем случае при косом соударении шара с тяжелой преградой закон преобразования углов видоизменяется: нормальная составляющая скорости уменьшается благодаря энергетическим потерям при сжатии материала шара и преграды, а касательная составляющая скорости уменьшается по причине трения шара о преграду в момент удара [2,3]. В случае малого трения потерями энергии в касательном направлении можно пренебречь, и при этом угол подлета всегда меньше угла отражения: $\theta_{i}<\theta_{r}$ [4].

Динамика косых соударений шара с преградой изучалась в многочисленных экспериментальных работах [5-14]. В настоящей работе экспериментально исследовались однократные косые соударения подвешенного на проводящей нити стального шара с тяжелой чугунной плитой и влияние наносекундного искрового разряда на характеристики соударения. Мотивация этих исследований заключается в том, что искровые разряды генерируют в воздушном промежутке между электродами ударные волны [15-18], которые могут повлиять на характеристики соударения.

Для проведения экспериментальных исследований был изготовлен и собран специальный стенд (рис. 1). Основу стенда составляет горизонтальный стол, на поверхность которого нанесена радиально-азимутальная разметка. Вблизи центра разметки была установлена вертикальная Г-образная опора, на которой на стальной нити подвешивался шар. Длина нити вместе с элементами подвеса и крепления составляла $L=255 \mathrm{~mm}$, а ее диаметр $-0.33 \mathrm{~mm}$. Для крепления верхнего конца нити к опоре и нижнего конца к шару использовались вертлюги, снимающие крутильные нагрузки в нити. Шар был выполнен из нержавеющей стали, имел диаметр $16 \mathrm{~mm}$ и массу 16.6 g. Поверхность шара была отполирована. В итоге опора, нить с элементами крепления и шар представляли собой маятник.

Вблизи точки равновесия маятника вертикально устанавливалась и закреплялась чугунная плита с плоской гладкой поверхностью так, чтобы в равновесном положении шар касался плоской поверхности плиты. Масса плиты $3.6 \mathrm{~kg}$.

Для генерации искровых разрядов использовался генератор высокого напряжения, работающий по принципу постоянной зарядки и самопробоя. Он использовался в [19-22]. Ранее было определено, что на уровне зарядного напряжения, например $\sim 5 \mathrm{kV}$, на нагрузке в виде воздушного промежутка $1 \mathrm{~mm}$ он генерирует униполярные искровые разряды с током $\sim 300$ А. Генератор подключался одним электродом к чугунной плите, а другим - к верхней точке подвеса. При этом напряжение к шару подводилось по нити через элементы крепления. Синхронизированные осциллограммы напряжения и тока искрового разряда при соударении шара с плитой приведены на рис. 2, $a$.

За движением шара следили с помощью закрепленного на Г-образной опоре видеорегистратора teXet DVR-905S, производящего видеозапись процесса c частотой $25 \mathrm{fps}$. Все эксперименты проводились в 


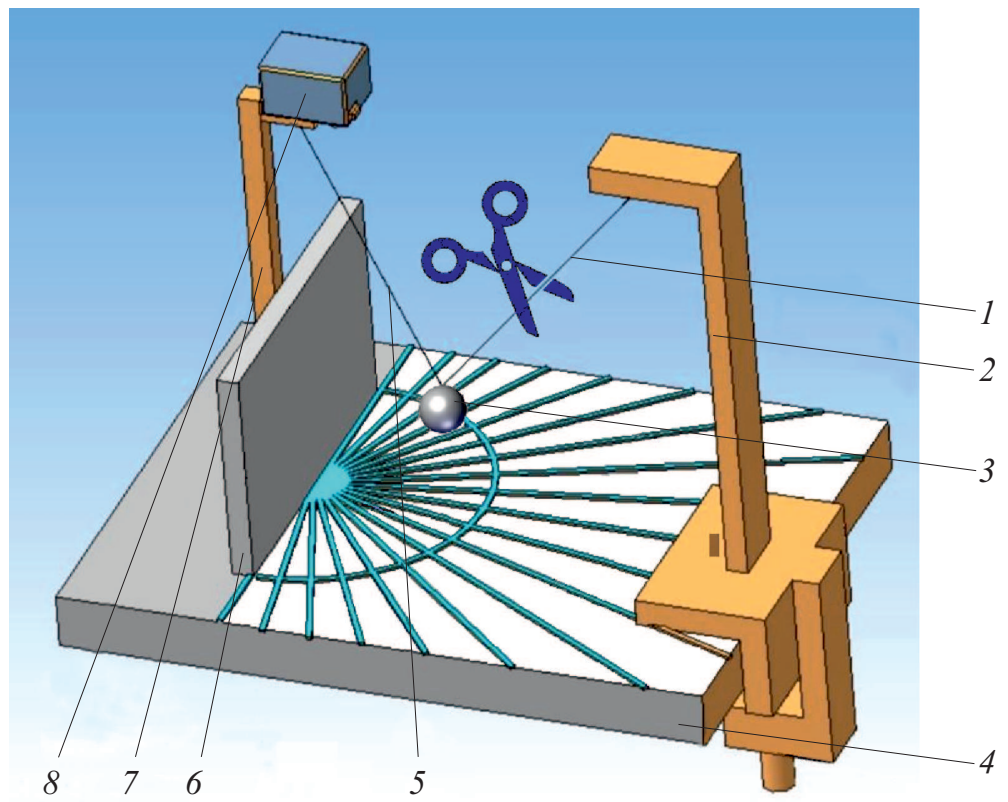

$a$
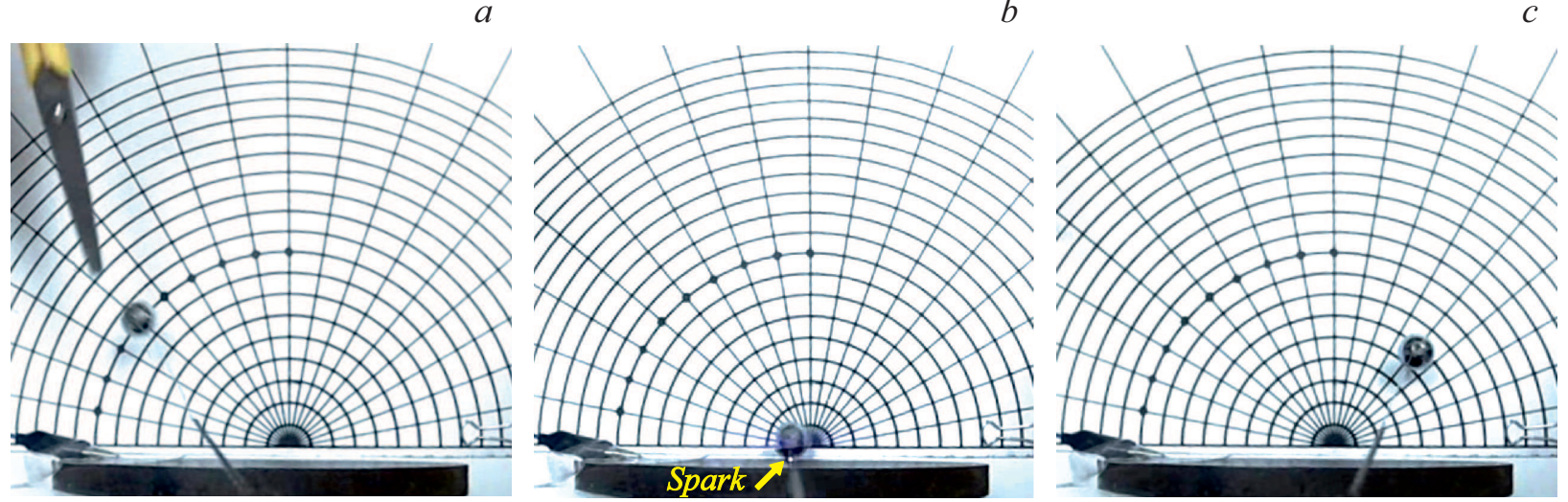

Рис. 1. Схема экспериментов: 1 - вспомогательная нить, $2-$ вспомогательная опора, 3 - стальной шар, 4 - горизонтальный стол с радиально-азимутальной разметкой, 5 - нить подвеса шара, 6 - чугунная плита, 7 - Г-образная опора, 8 - видеорегистратор. На вставках представлены отдельные фазы соударения: $a-$ начальное положение шара (видны ножницы, перерезающие вспомогательную нить); $b$ - положение шара в момент удара, стрелкой показан микроканал искрового разряда; $c-$ положение шара в момент первой остановки.

помещении при атмосферном давлении 750 Torr и температуре $20^{\circ} \mathrm{C}$.

В видеорегистратор встроен микрофон. С его помощью можно регистрировать и акустические сигналы от удара. Осциллограммы акустических сигналов первого удара шара о плиту без разряда и с разрядом, полученные с помощью этого микрофона, представлены на рис. $2, b$.

Удар без разряда возбуждает в металле почти монохроматический акустический звон (аналогичный колокольному звону) на частоте $2854.2 \mathrm{~Hz}$, который немонотонно затухает. Немонотонность затухания объясняется многочисленными переотражениями от криволинейных поверхностей.

В случае же с разрядом процесс идет следующим образом. Разряд возникает при подлете шара к плите несколько раньше механического удара. Поэтому пер- вичная ударная волна в воздухе видна на осциллограмме еще до начала акустического звона. Ударную волну легко отличить от звона, так как ее длительность больше полупериода звона. Вторичные ударные волны, возникающие в результате переотражений, незаметны на фоне более высокочастотного и более громкого звона. Приведенные осциллограммы подтверждают генерацию ударных волн в искровых разрядах.

Эксперименты осуществлялись следующим образом. Сначала маятник отклонялся от вертикали на угол $20^{\circ}$ и от нормали к плоскости плиты на заданный азимутальный угол $\theta_{i}$. В этом положении маятник закреплялся с помощью вспомогательной текстильной нити. Затем подавалось высокое напряжение между плитой и шаром.

После полного затухания установочных колебаний шара производился запуск стенда путем механического перерезания вспомогательной нити. При этом шар при- 
ходил в движение к плите без начальной скорости и без вращения, соударялся с плитой и отскакивал от нее под другим азимутальным углом $\theta_{r}$. В момент соударения происходил однократный искровой разряд.

Регистрация движения происходила от момента перерезания вспомогательной нити до момента первой остановки шара после соударения. Отдельные кадры процесса соударения с искровым разрядом представлены на вставках $a-c$ к рис. 1. По видеоизображениям измерялись углы подлета $\theta_{i}$ и отражения $\theta_{r}$.

Результаты измерений углов подлета $\theta_{i}$ и отражения $\theta_{r}$ представлены на рис. 3. В отсутствие разряда кривая зависимости $\theta_{r}$ от $\theta_{i}$ целиком лежит выше идеальной прямой $\theta_{r}=\theta_{i}$ в соответствии с [4]. Однако оказалось,

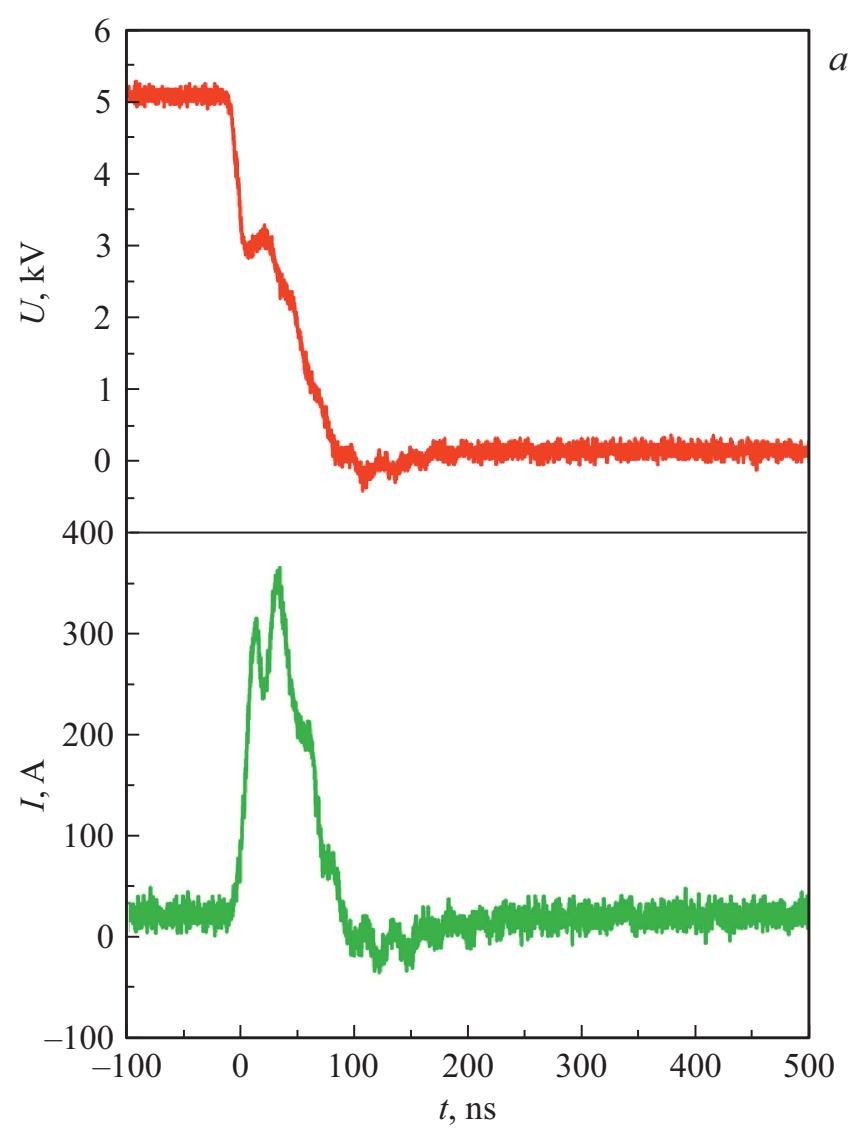

$b$
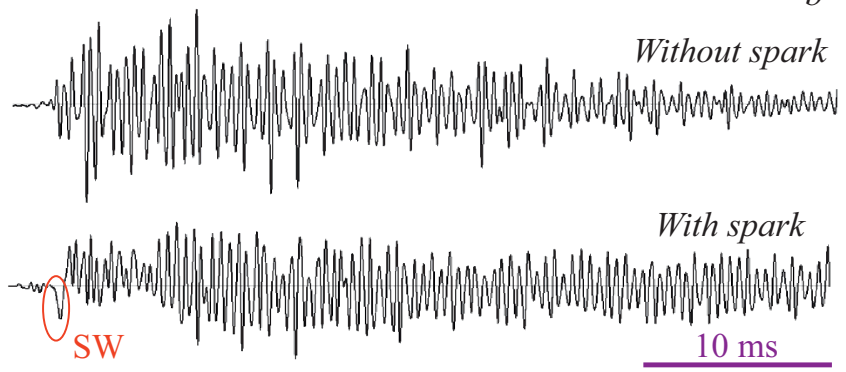

Рис. 2. $a-$ синхронизированные осциллограммы искрового разряда: напряжения (вверху) и тока (внизу); $b$ - осциллограммы акустических сигналов удара без разряда (вверху) и с разрядом (внизу), SW - ударная волна в воздухе.

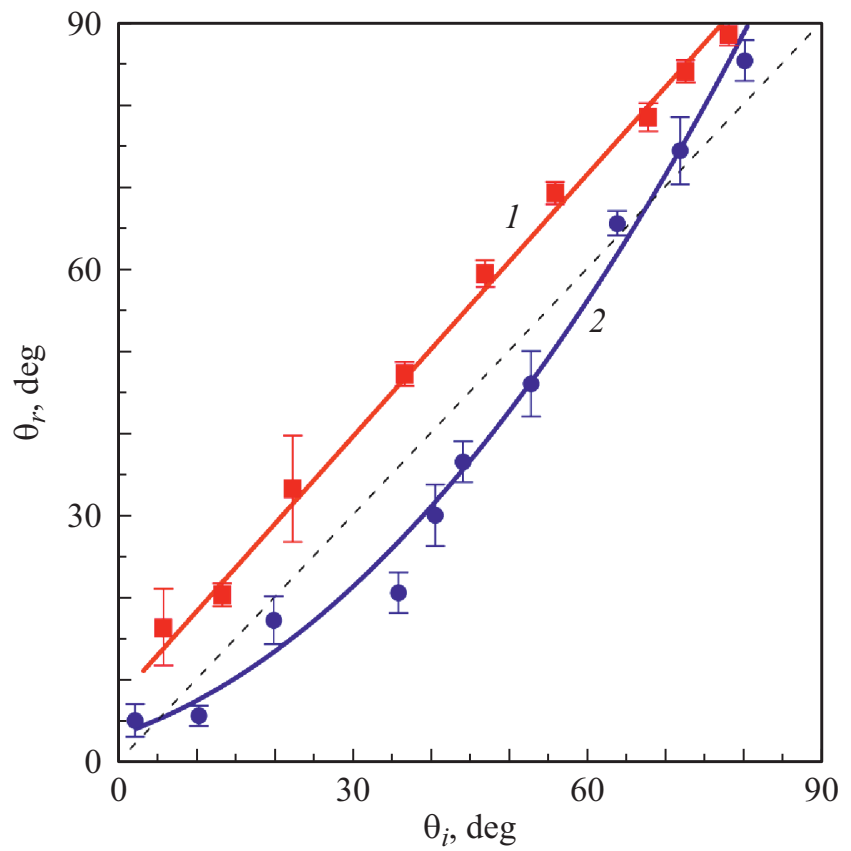

Рис. 3. Зависимость угла отражения $\theta_{r}$ от угла подлета $\theta_{i}$. 1 - без разряда, $2-$ с разрядом.

что в случае с искровым разрядом кривая зависимости $\theta_{r}$ от $\theta_{i}$ почти вся лежит, наоборот, ниже идеальной прямой. Кадры процесса соударения с искровым разрядом, представленные на вставках $a$ и $c$ к рис. 1, как раз и демонстрируют неравенство $\theta_{i}>\theta_{r}$.

Обнаруженное аномальное поведение зависимости $\theta_{r}$ от $\theta_{i}$ свидетельствует об индуцированном искровым разрядом „смягчении“ соударения. Анализ видеоизображений показал, что разряд приводит к увеличению кинематического коэффициента восстановления для нормальной составляющей скорости и уменьшению кинематического коэффициента восстановления для тангенциальной составляющей скорости. Фактически разряд, создавая ударную волну, демпфирующую удар, уменьшает неупругие потери энергии в нормальном направлении, но электростатическое притяжение шара к плите приводит к их кратковременному сцеплению в момент удара, что увеличивает силу трения шара о плиту. Энергетический коэффициент восстановления для полной кинетической энергии шара, который можно вычислить по формуле

$$
k_{E}=\frac{H_{r}}{H_{i}}=\frac{L-\sqrt{L^{2}-R_{r}^{2}}}{L-\sqrt{L^{2}-R_{i}^{2}}}
$$

(где $H_{r} / H_{i}$ - отношение высот максимального подъема шара после первого удара и в момент старта, выраженных через радиальные координаты этих положений $R_{i, r}$ ), имеет, например, при $\theta_{i}=50^{\circ}$ значения 0.42 (без разряда) до 0.52 (с разрядом).

Таким образом, при экспериментальном изучении влияния наносекундного искрового разряда на косое соуда- 
рение стального шара с плоской чугунной плитой было обнаружено, что угол отражения шара при столкновении с разрядом становится меньше угла подлета, в то время как при обычном соударении без разряда, наоборот, угол отражения больше угла подлета.

\section{Конфликт интересов}

Авторы заявляют, что у них нет конфликта интересов.

\section{Список литературы}

[1] G. Coriolis, Théorie mathématique des effets du jeu de billard (Carilian-Goeury, Paris, 1835).

[2] W.J. Stronge, Impact mechanics (Cambridge University Press, Cambridge, 2008).

[3] C. Lakshmana Rao, V. Narayanamurthy, K.R.Y. Simha, Applied impact mechanics (Wiley, 2016).

[4] С.М. Тарг, Краткий курс теоретической механики (Высш. шк., М., 2010).

[5] R.C.J. Howland, T.W.C. Dickson, London, Edinburgh, and Dublin Phil. Mag. J. Sci., 2 (11), 1091 (1926). DOI: $10.1080 / 14786442608564139$

[6] N. Maw, J.R. Barber, J.N.Fawcett, Wear, 38 (1), 101 (1976). DOI: $10.1016 / 0043-1648(76) 90201-5$

[7] G. Sundararajan, P.G. Shewmon, Int. J. Impact Eng., 6 (1), 3 (1987). DOI: 10.1016/0734-743X(87)90003-0

[8] A.D. Lewis, R.J. Rogers, J. Sound Vibr., 125 (3), 403 (1988). DOI: $10.1016 / 0022-460 \mathrm{X}(88) 90250-7$

[9] D.A. Gorham, A.H. Kharaz, Powder Technol., 112 (3), 193 (2000). DOI: 10.1016/S0032-5910(00)00293-X

[10] M.Y. Louge, M.E. Adams, Phys. Rev. E, 65 (2), 021303 (2002). DOI: 10.1103/PhysRevE.65.021303

[11] H. Dong, M.H. Moys, Powder Technol., 161 (1), 22 (2006). DOI: 10.1016/j.powtec.2005.05.046

[12] A. Rezaei, R. Verhelst, W. Van Paepegem, J. Degrieck, J. Sports Sci., 29 (11), 1201 (2011). DOI: $10.1080 / 02640414.2011 .587443$

[13] R. Cross, Exp. Mech., 54 (9), 1523 (2014). DOI: $10.1007 / \mathrm{s} 11340-014-9938-3$

[14] R. Cross, Am. J. Phys., 83 (3), 238 (2015). DOI: $10.1119 / 1.4898312$

[15] A.E Dubinov, S.A. Sadovoy, V.D. Selemir, Shock Waves, 10 (1), 73 (2000). DOI: 10.1007/s001930050180

[16] Q. Liu, Y. Zhang, J. Appl. Phys., 116 (15), 153302 (2014). DOI: $10.1063 / 1.4898141$

[17] E.V. Parkevich, M.A. Medvedev, G.V. Ivanenkov, A.I. Khirianova, A.S. Selyukov, A.V. Agafonov, Ph.A. Korneev, S.Y. Gus'kov, A.R. Mingaleev, Plasma Sources Sci. Technol., 28 (9), 095003 (2019). DOI: 10.1088/1361-6595/ab3768

[18] J. Huang, L. Yang, H. Zhang, L. Chen, X. Wu, Chin. Phys. B, 28 (5), 055202 (2019). DOI: 10.1088/1674-1056/28/5/055202

[19] A.E. Dubinov, J.P. Kozhayeva, V.V. Golovanov, V.D. Selemir, IEEE Trans. Plasma Sci., 47 (1), 76 (2018).

DOI: $10.1109 /$ TPS.2018.2868443

[20] А.Е. Дубинов, Ю.П. Кожаева, Письма в ЖТФ, 45 (8), 16 (2019). DOI: 10.21883/PJTF.2019.08.47614.17704 [A.E. Dubinov, J.P. Kozhayeva, Tech. Phys. Lett., 45 (4), 383 (2019). DOI: 10.1134/S1063785019040242].
[21] Č. Kodejška, Matematika-Fizika-Informatika, 28 (3), 201 (2019). http://mfi.upol.cz/files/28/2803/mfi_2803_201_206.pdf

[22] R. Nath, M.M. Patidar, N.K. Ghodke, S.C. Das, V. Ganesan, Asian J. Conv. Technol., 6 (2), 28 (2020). DOI: 10.33130/AJCT.2020v06i02.005 